\title{
Research on Color Application in Children's Food Packaging Design
}

\author{
Chunfeng Lv $\mathbf{1}^{1,}$ a \\ ${ }^{1}$ College of Art and Design, Nanyang Institute of Technology, China \\ axiangyanghua666@163.com
}

Keywords: children's food packaging, color psychology, color characteristics, packaging design

\begin{abstract}
Color is an important factor in the design of food packaging. Food packaging with appropriate colors will attract people's attention. At the same time, consumers will also be deeply impressed by the choice of goods in the supermarket, which in turn will promote their purchase behavior. With the maturity of research on color psychology, research on the use of color has also entered the field of food packaging. Children have a special preference for colors. Researching colors and using good colors is especially important for children's food packaging design. This paper expounds the important role of color in children's food packaging, and analyzes and concludes the thinking of color aesthetic features, color visual features, and taste characteristics in children's food packaging, and puts forward some specific feasible color suggestions.
\end{abstract}

\section{Introduction}

With the improvement of people's living standards, more and more families are no longer the kind of self-sufficient environment they used to produce things. The more developed the commodity economy, the more frequently people buy food outside. When people buy food, they are concerned not only with the quality of the food itself, but also with the food packaging. The use of food packaging colors has a decisive effect directly on the choice of food buyers [1]. This is particularly evident in children's food. Today we are exploring this issue here, and we want everyone to be more fully aware of the importance of color for children's food.

\section{Children's Consumer Psychology and Color}

In the market competition, the design of packaging is actually for sales service. Researching the consumption psychology of children is the premise of our packaging design. Designing for children's consumer psychology will create packages that will appeal to children, which will facilitate sales.

\subsection{Strong curiosity.}

Curiosity and fun things can have a strong attraction for children. For new things, children often show greater enthusiasm and inquiry psychology than adults [1]. Therefore, in the design or production of children-related products, usually interesting, this interest mainly refers to the design or production of goods can be used as toys, very interesting. In addition, the designed children's goods require new differences. Common things are often not attractive to children. Some things that are not seen in life can often attract children's attention. This can be confirmed by children's love of watching cartoons. Similarly, in the packaging design of children's food, we must choose some interesting and fun appearance, and with a special eye-catching colors.

\subsection{Select the ambiguity of the product.}

Children have strong self-esteem. Under normal circumstances, they do not want to be denied, so they are hesitant when choosing goods. The scene we can often see is that children are overwhelmed in front of a row of goods and may have given up a lot of goods before deciding to buy one of them. Similarly, for the consumer psychology of children, good packaging design is very important, and a package that appeals to children will allow children to make decisions without hesitation [2]. 


\subsection{Extremely imitative.}

What does the partner have, he also wants it. Children want to be consistent with others, but also want to be consistent with adults, such as parents or a celebrity. In this way, they will feel equal, while instinctive consumption gradually matures, social consumption has also been greatly developed, especially in the preschool period when there is a clear comparison and showing off [2]. The social needs of school-age children are rich and diverse. For example, if you see a gun or a pet in a movie or anime, the child will ask for it to keep himself in line with others.

\subsection{Poor stability.}

Children's consumption is purely emotional. It has a fast interest in one thing and loses interest. The child also displays the difference between himself and other children or others by purchasing or owning certain goods. For example, they would want to distinguish a pedal-bicycle from a child's pedal tricycle, but it didn't take long for him to have another idea. This makes it necessary for us to constantly update the design style of children's related products in order to follow the children's changing preferences [1].

Compared to adults, children's feelings about color are very sensitive. In real life, we see that children's favorite things are often very colorful things. Similarly, in shopping malls, children's products special areas are usually the most colorful places; this is because businesses have captured the consumer psychology of children's color preferences. In fact, the richness of color is directly proportional to the desire of children to buy. The richer the colors the more able children to evoke children's imagination and illusions, they can make children feel happy and happy. Here, we can also draw lessons from the result of an experiment [3]. That is, children's perception of a commodity is firstly color and then it is a shape. Within 20s of the initial contact with a child, the color perception is $80 \%$, and the perception is $20 \%$; within 3 minutes, the color perception is $60 \%$, and the sense is $40 \%$. Therefore, merchandise packaging must be "color" to win people, in one fell swoop to live in the heart of the target children. At the same time, the color of the package should be adapted to the purpose and characteristics of the product itself, and it should be evoked by stimulating the vision to affect the child's likes and requirements for the product.

\section{Characteristics of Children's Food Packaging Color}

Through the analysis and study of specific children's food packaging cases, we found that the packaging color law can be used as reference for future packaging design [2]. For example: The pudding packaging of Dr.Oetker in Germany is very powerful for people's visual effects. We can feel the taste and quality from the color of the package. Packaging colors can express the taste of food.

Children's food packaging on the market now starts from the inherent color of food, and its color is refined and sublimated. It looks more colorful and lively, and it can attract children's attention. In color design, Children's foods are mostly bright red, yellow, gold, apple green, light purple or rose. Because the three primary colors and contrasting colors are more suitable for children's visual psychology, they can also affect children's color memory. Each color will give people different taste hints [3]. Regarding the feeling of color, Japanese colorist Naito Konjiro found that the sweetness is yellow, white and pink, the acid is green, the bitterness is tea, gray, black, salty is white, Blue, tea, blue. The experimental result of the colorist Esbirk is: Sweet is orange-red, acid is green, blue-green, and bitter is black. "Salty is blue. The experimental result of Goulin is:" Sweet is pink, "Sour" It is green. Bitterness is blue-purple and salty is blue. The packaging color directly affects the children's choice of food tastes. Therefore, color design should be based on understanding the characteristics of color taste.

New lifestyles and modern consumer attitudes have greatly enriched modern food packaging. Children's food packaging is also constantly developed and innovated. In its packaging design, it is necessary to accurately convey information, but also have advanced design ideas and guide consumption concepts. It should be fun, cultural, functional, and healthy [4]. Its packaging color must be reasonably applied and grasped from the development and innovation of materials, and it must be 
inspired and applied in new situations.

In modern children's food packaging materials, most of them are packaged in plastic and paper because of their strong color. From an environmental point of view, we advocate the use of paper products and natural material packaging [4]. A lot of foreign paper product packaging, instead of using a single white, but using colorful paper packaging, not only with their civilian habits, a scientific point of view reflects the color of food packaging paper more attractive to consumers.

\section{The role of color in children's food packaging}

Among the design elements mentioned above, different design elements play different roles in the whole package. Among them, due to the choice of children's food, the color of the package that gives the first visual effect is more appealing to consumers, and then It is a graphic and explanatory text. Therefore, in the packaging design of children's food, it is necessary to use packaging colors reasonably and accurately, and pay attention to the use of color [5]. We can see that all the consumer products related to children look very colorful and have little black and white or colorless appearance, because manufacturers understand that children's passion for color far exceeds the product itself.

In children's food packaging, color can not only impress the children of this group of consumers, but also has the following functions.

\subsection{The effect of packaging color on children's food promotion.}

Researchers have done a simple experiment: put two food packaging of the same shape but different colors on a table (fig.1). One package is grayish-white and one is red, yellow and green. Let a three children choose. Without exception, these three children chose the more colorful packaging and did not feel that almost colorless packaging. This experiment shows that color is an important determinant when children pick goods [5]. The above experiments and survey results tell us that children's food packaging must have the color to impress children, so as to win the children's hearts in the shortest possible time. To give a simple example, this year, many children's favorite snack foods a lot of fish, its packaging is based on red, blue, green as the main color, in these relatively bright main colors above is a lovely yellow whales The image, together with the yellow tones of the "Much Fish" internal food, makes the whole package look rich and colorful, which greatly satisfies the child's preference for color.
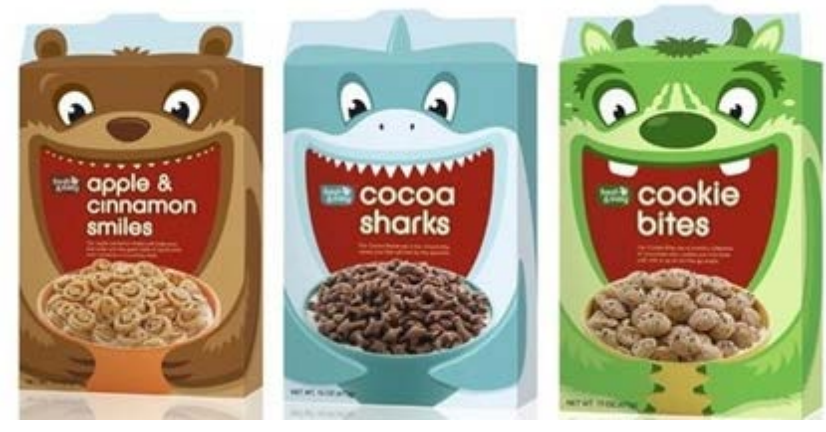

Fig 1. The promotion of packaging

\subsection{Color is the key to unlock children's hearts.}

On the basis of not increasing the cost, the improved color design can bring more added values to the product. Different from adults, children and adults are not mature enough, lack experience in life, and have a simple understanding of color. They rarely pay attention to the multi-level grey tone of life, and they do not consider the significance of color [6]. Compared with ordinary food packaging, the color of children's food packaging shows obvious childishness to cater to children's consumer psychology. With the continuous development and innovation of children's food packaging, the functional status of color is getting higher and higher.

\subsection{Taste cues in children's food packaging.}

The packaging of food as the "outerwear" of food is the first element for people to recognize this 
kind of food. It enables people to understand the type, shape and even the taste of food after seeing this package. How can the taste of food be identified by the packaging? What is used here is the taste-introducing function of color [6]. The so-called color taste-implication function refers to the long-term accumulated visual experience of people. Different colors usually give people different taste experience. For example, purple is the color of grapes. In food packaging, purple usually represents grape flavor, yellow is the color of banana, usually yellow represents banana flavor, red is the color of chili, and red usually represents spicy flavor. In addition to the color experience from the natural world, the previous buying experience is also an important source of tasting. For example, the foods that were seen in all the blues food packages that were seen before were salty. After seeing the other blue tone packaging, basically it can be judged that this food is salty, shown as Fig. 2.

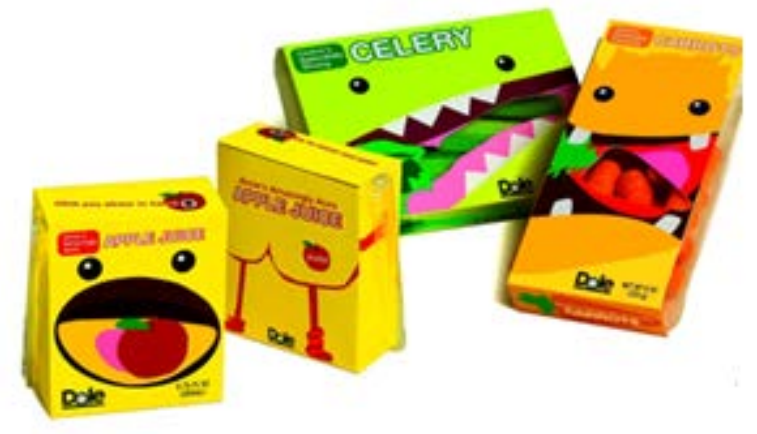

Fig. 2 Taste cues in children's food packaging

\subsection{Proper color prompt brand.}

Today, with the rapid development of commodity economy, every company wants to increase the popularity of its own products and make its own products well-known, and the packaging of commodities is undoubtedly the best way to expand the popularity of the company, shown in Fig 3). The color design of successful merchandise packaging enables consumers to look for brands [7]. Consumers can have a sense of identity and familiarity when they see this color. This sense of identity and familiarity is an important driving force for consumer spending.

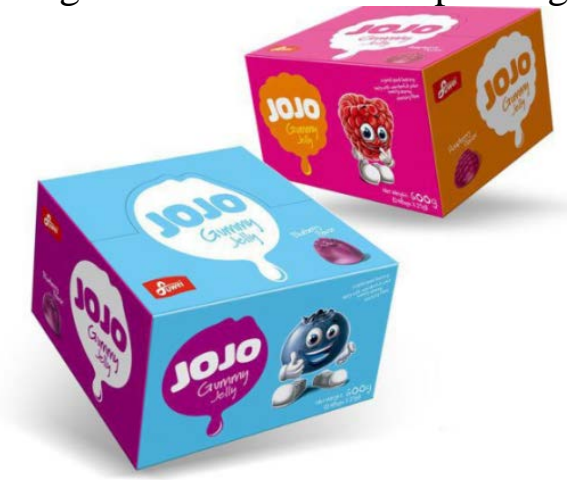

Fig.3 Proper color prompt brand

\subsection{Increase the attractiveness of children.}

Some colors have special appeal for children, such as red, orange, grass green, and sky blue. Red and orange are easy to cause children's attention and appetite, resulting in a sense of excitement, warmth, and deliciousness. They can be used in a large area in children's food packaging. The combination of primary colors and contrasting colors is more suitable for children's visual psychology and can also affect children's color memory, as Fig. 4. These colorful, lively and innocent colors are organically integrated with other elements to form the distinctive features of children's food packaging and are loved by most children. Children's food packaging is the most colorful and innovative in all food packaging [7]. They attract children's curious eyes with silent color language, which brings a huge market space to the business. 


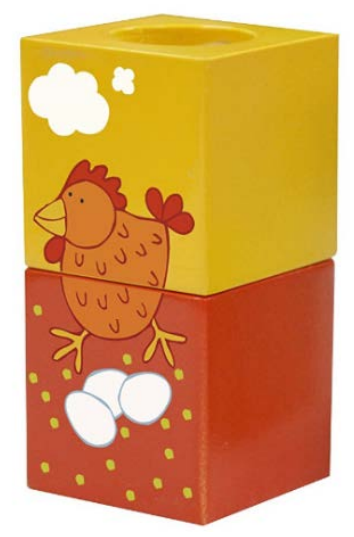

Fig. 4 Increase the attractiveness of children

\section{Conclusion}

Through analysis and research on children's food packaging, we can conclude that modern children's food packaging is not in the traditional sense. It is entertainment fun, culture, functionality, and health. It puts forward the color of packaging. The new requirements and guidelines must have advanced thinking in the continuous creation of the future. They should be considered and designed from the perspective of consumers, and should use new collocations to actively develop new materials and collaborate on colors and shapes. With its color matching, learning the experience of foreign packaging colors, taking the road of nationalization of characteristics, we can remain invincible in the era of economic globalization.

\section{References}

[1] X.Y. Cai, Taste psychology of food packaging design, packaging engineering, 2004, vol.11, pp.137-138.

[2] L.G. Ding, Integrating happy emotion into packaging design, Packaging Engineering, 2005, vol.3, pp.8-9.

[3] J.T. Li, Humanized Design Concept of Packaging Colors, Proceedings of the First Asian Color Forum, 2004, pp.25-30.

[4] H.Y. Shang, Source of Packaging Color Creation and Its Enlightenment, Packaging Engineering, 2005, vol.3, pp.17-19.

[5] E.P. Yuan, Q.J. Chen, Research on Practical Courses of Modern Packaging Design Education, Packaging Engineering, 2004, vol.5, pp.24-26.

[6] E.P. Yuan and H.T. Li, Market positioning of specialty toy packaging design, Packaging engineering, 2005, vol.3, pp.15-16.

[7] H.Q. Tian, the application of color psychology in the design, Journal of Xingtai University, 2007, vol.3, pp.12-13. 